
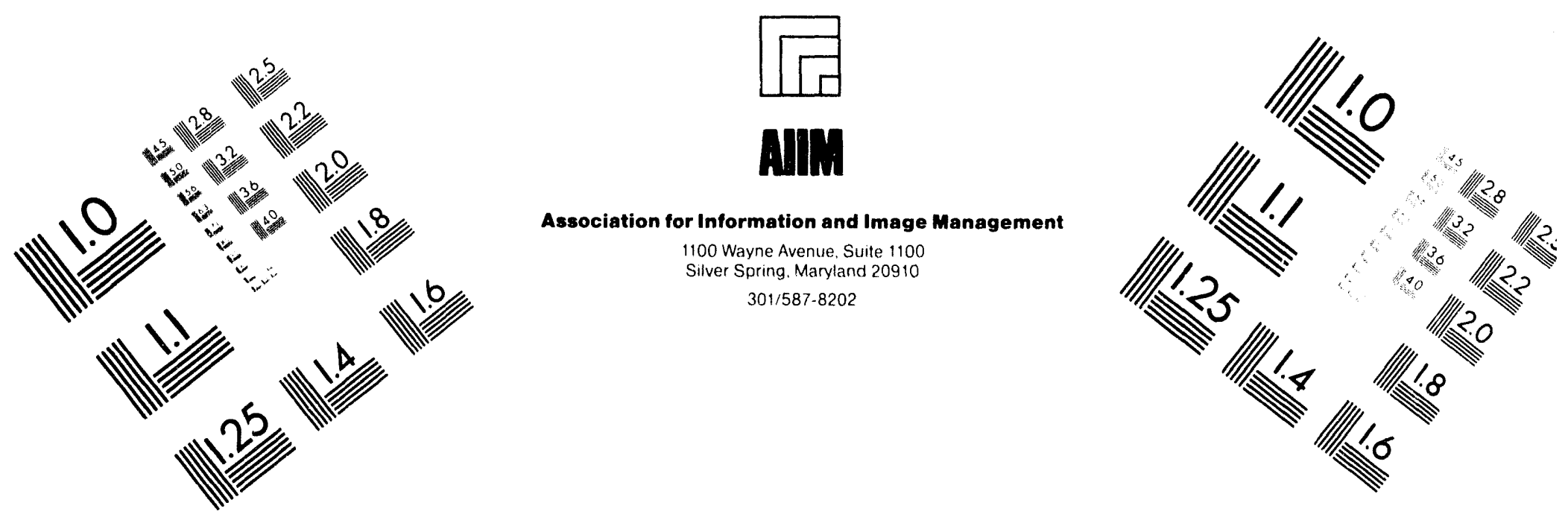

\title{
Centimeter
}

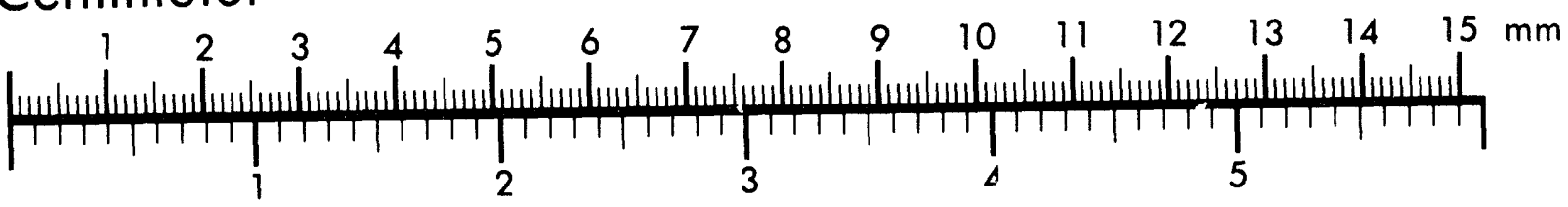
Inches
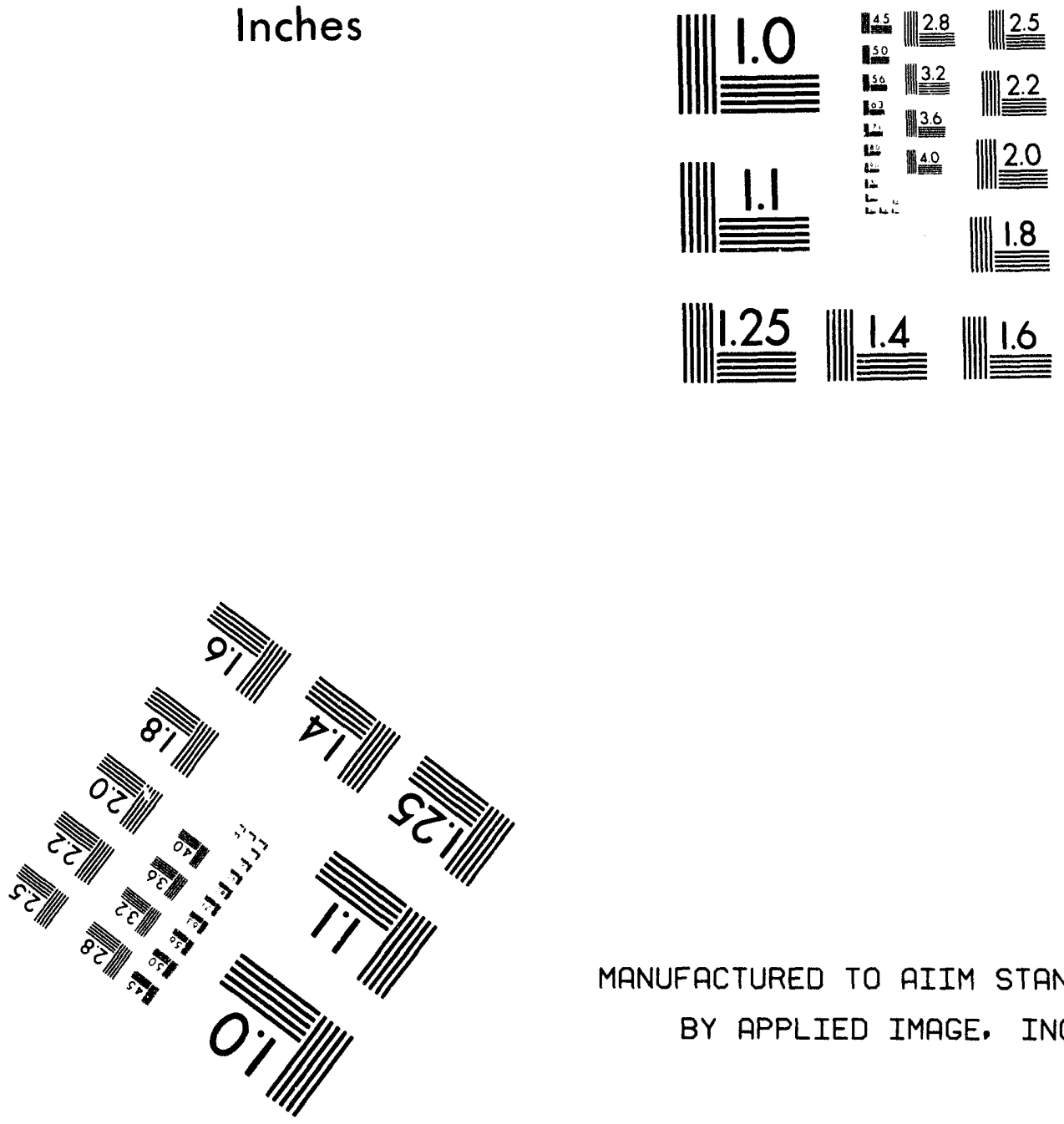

MANUFACTURED TO AIIM STANDARDS

BY APPLIED IMAGE. INC.

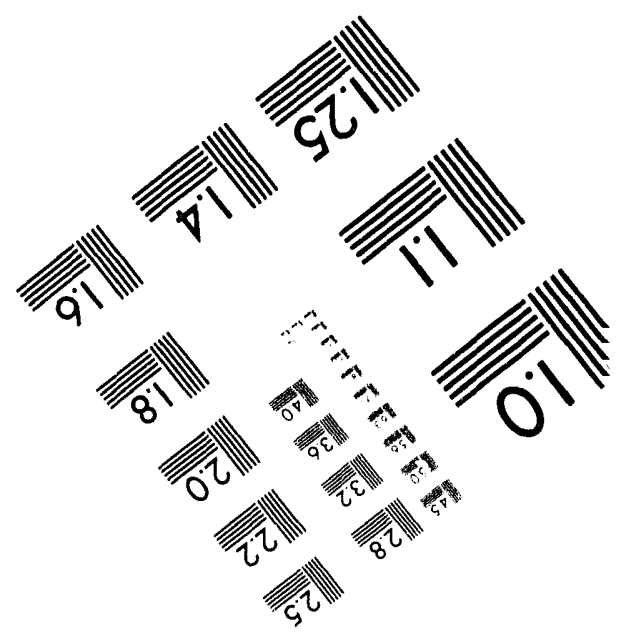



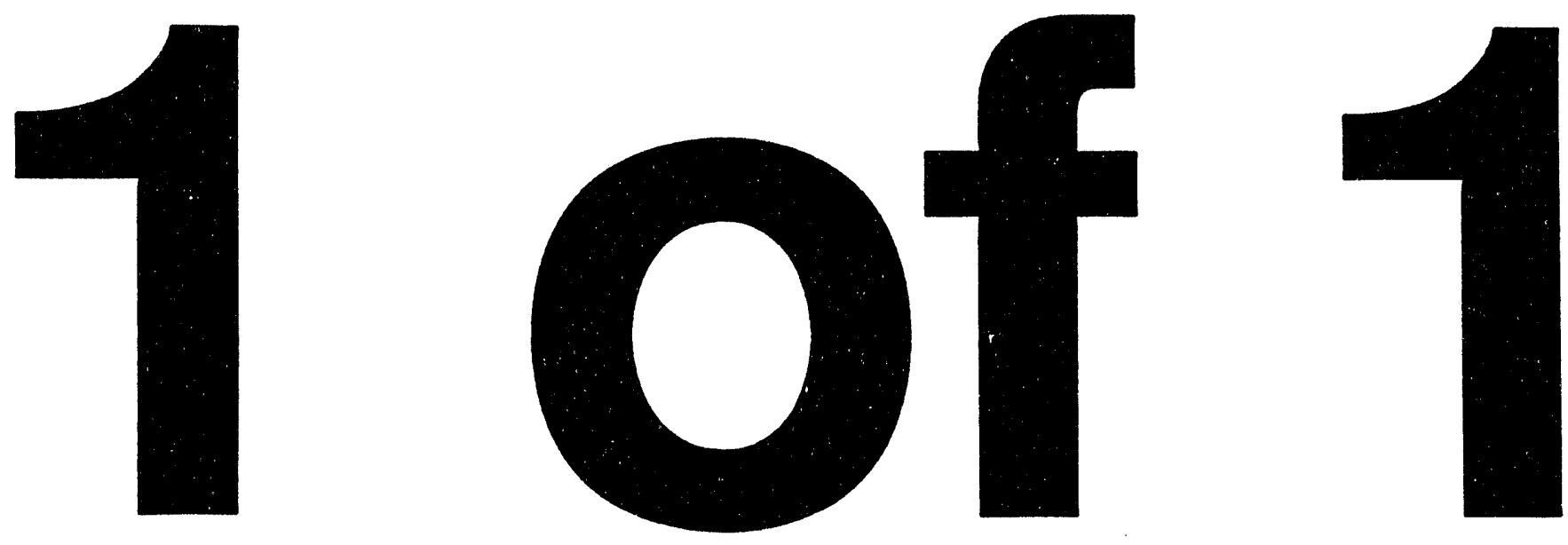


\title{
Isotopic Mass and Alpha Heating Effects in TFTR DT Plasmas
}

(to be published in the proceedings of the 21th EPS Conference on Controlled Fusion and Plasma Physics)

R. V. Budny, M. G. Bell, D. K. Mansfield, J. D. Strachan, S. Zweben, H. Adler, C. E. Bush, Z. Chang, D. Ernst, E. Fredrickson, B. Grek, L. R. Grisham, R. J. Hawryluk, D. L. Jassby, L. C. Johnson, D. C. McCune, M. Murakami, H. Park, A. T. Ramsey, J. Schivell, S. D. Scott, C. H. Skinner, E. Synakowski, G. Taylor, and M. C. Zarnstorff

Princeton University Plasma Physics Laboratory P. O. Box 451, Princeton NJ 08543, USA

\begin{abstract}
Sets of simila: TFTR discharges with varying amounts of $D$ and $T$ are compared. The $T$ content is altered by varying the mix of $D$ and $T N B I$ at approximately constant total NBI power. The total plasma current, toroidal field, central $Z_{\text {eff, }}$ and wall conditions are very similar in each set. The electron density profiles are approximately similar. The sets contain pairs of discharges with D-only and DT-NBI. Several sets also contain discharges with T-only NBI.

The discharges are analyzed using the TRANSP plasma analysis code. Good agreement with measured parameters is achieved. Profiles are computed for the isotopic mass of the hydrogenic thermal species $A$, and for the hydrogenic thermal plus beam species $A_{\text {tot }}$. Their volume averages increase approximately linearly as the fraction of T-NBI power increases, and they are slightly peaked for DT and Tonly NBI discharges. The total energy and the total energy confinement time increase approximately linearly with $A_{\text {tot }}$ up to $30 \%$. The beam fraction of the total energy at $0.5 \mathrm{sec}$ of $\mathrm{NBI}$ remains relatively constant, $\approx 40-50 \%$ as $A_{\text {tot }}$ varies. The thermal ion fraction increases slightly, and the electron fraction decreases. The isotopic and alpha heating effects contribute in roughly equal amounts to the increase in central $\mathrm{T}_{e}$.
\end{abstract}




\section{Isotopic Mass and Alpha Heating Effects in TFTR DT Plasmas}

R. V.Budny M. G. Bell, D. K. Mansfield, J. D. Strachan, S. Zweben, H. Adler, C. E. Bush, a Z. Chang, D D. Ernst, C E. Fredrickson, B. Grek,

L. R. Grisham, R. J. Hawryluk, D. L. Jassby, L. C. Johnson, D. 'C. McCune, M. Murakami, D H. Park, A. T. Ramsey, J. Schivell, S. D. Scott,

C. H. Skinner, E. Synakowski, G. Taylor, and M. C. Zarnstorff

Princeton University Plasma Physics Laboratory

P. O. Box 451, Princeton NJ 08543, USA

\section{Introduction}

Experiments with deuterium-tritium (DT) plasmas started in TFTR during 1993 $[1,2]$. Recent results with neutral beam injection (NBI) heated DT discharges have produced $9 \mathrm{MW}$ of fusion power with a peak power density of $1.8 \mathrm{MW} / \mathrm{m}^{3}$. The stored energy and the energy confinement time in these plasmas is observed to increase up to $30 \%$ above the values in comparable D-only NBI discharges. The central ion and electron temperatures also increase.

The thermonuclear fraction of the neutron emission rate reaches $35 \%$ of the total. At the times of peak stored energy and neutron emission, the beam energy is $25-45 \%$ of the total. The beam ion deposition, slowing down, and plasma heating change as the isotopic mix of the beam ions varies, so it is important to include beam ion effects in assessing isotopic scaling and alpha heating.

This paper analyzes the phenomenology of these increases in energy, confinement, and temperatures using the TRANSP time-dependent plasma analysis code [3]. The modeling provides detailed information about the beam ions, as well as profiles of the $D$ and $T$ densities, the hydrogenic isotopic mass, and the alpha heating. These are correlated with the observed increases.

To study the isotopic effect and alpha heating, sets of similar discharges with varying amounts of $D$ and $T$ are compared. The $T$ content is altered by varying the mix of D and T NBI at approximately constant total NBI power, $P_{B}$. The total plasma current $I_{p}$, toroidal field $B_{T}$, central $Z_{\text {eff, }}$ and wall conditions are very similar in each set. The electron density profiles are approximately similar. The sets contain pairs of discharges with D-only and DT-NBI. Several sets also contain discharges with T-only NBI.

\section{TRANSP modeling and comparisons with measurements}

The TRANSP code uses measured plasma parameters and minimal additional assumptions to model discharges. The time evolutions of particle and energy profiles are computed in one dimension. For the results described here, the modeling includes the thermal $H, D$, and $T$, the fast $D$ and T ions from the NBI, the fusion alpha particles, and carbon impurity. Measured profiles of the electron density (from infrared interferometry), electron temperature (from electron cyclotron emission) and of the carbon temperature and toroidal rotation velocity (from chargeexchange recombination spectroscopy) are used. The $Z_{\text {eff }}$ is deduced from the visible bremsstrahlung emission. The neutral beam parameters are calculated using Monte Carlo techniques.

Hydrogenic recycling has important effects, such as introducing $D$ into T-only NBI discharges, and relatively small, but significant amounts of T into D-only NBI discharges. The hydrogenic recycling rates are calculated from the measured $H_{\alpha}+D_{\alpha}+T_{\alpha}$ emission, converted to ionization rates using the DEGAS neutrals code [4]. Spectroscopy indicates that about $18-35 \%$ of this emission is from $\mathrm{H}$, and at most $\approx 7 \%$ is from T [5]. For the TRANSP modeling of D-only NBI discharges, the T fraction is assumed to be constant during each discharge, and is adjusted from discharge to discharge to match the measured peak DT neutron s ission rate. The resulting values are within $30 \%$ of the values measured using a Fabry-Perot 
interferometer [5]. The modeling of DT- and T-only NBI discharges is insensitive to the choice of this parameter.

There are $u$ icertainties about the particle transport of the hydrogenic species. Several classes of models are available in TRANSP. Only one is successful in modeling all the discharges. The thermal hydrogenic density is determined from the symmetrized electron density, and the computed $Z_{\text {eff, }}$ and beam ion density. The relative $H, D$, and $T$ fluxes can be specified by assuming either 1) their profile shapes are the same, 2) their radial velocities are the same, or 3) by constraining $D_{j}$ and $V_{j}$ in

$$
\Gamma_{j}(x, t)=-D_{j} * \operatorname{grad}\left(n_{j}\right)+V_{j} * n_{j}, \text { with } j=H, D, T
$$

The choice 1) is unsuccessful in modeling the neutron emission, especially for the $T$ only NBI discharges. Choice 2) is numerically unstable in the case of three thermal hydrogenic species, and has not been studied in detail. A non-unique set of constraints for choice 3) gives good agreement with measurements, and is used for the results presented here.

Examples of comparisons that test the accuracy of the modeling are the neutron emission rates and profiles, which test the accuracy of the calculated beam and thermal ion density distributions, and the stored energy and the Shafranov shifts, which test the calculated beam ion energy. The results generally agree with measurements to $1.5 \mathrm{\sigma}$. Examples of neutron emission comparisons for one of the discharges in a triplet are shown in Fig. 1. Each discharge in this triplet has $R=2.52$ $\mathrm{m}, \mathrm{a}=0.87 \mathrm{~m}, \mathrm{I}_{\mathrm{p}}=2.1 \mathrm{MA}, \mathrm{B}_{\mathrm{T}}=5.1 \mathrm{~T}, \mathrm{P}_{\mathrm{B}}=21 \mathrm{MW}$, and lithium pellet wall conditioning. The agreement shown is typical of the results achieved, even for the Donly and T-only NBI discharges.

\section{Isotopic Mass Effects}

The computed thermal hydrogenic profiles are dissimilar for the hydrogenic particle model used due to their different sources. An example is shown in Fig. 2 for the discharge in Fig. 1 at the time of peak neutron emission. The discharges in this triplet have an unusually large amount of $H$ recycling, with moasured $H_{\alpha} /$ $\left(H_{\alpha}+D_{\alpha}+T_{\alpha}\right)=35 \%$. The relative $T$ density can be summarized by the average isotopic mass of the thermal hydrogenic species,

$$
A \equiv\left(n_{H}+2 n_{D}+3 n_{T}\right) /\left(n_{H}+n_{D}+n_{T}\right)
$$

Profiles of $A$ at several times for the triplet are shown in Fig. 3.

Since there is uncertainty about the degree to which the beam ions contribute to the isotopic effect, we consider also $A_{\text {tot }}$ defined analogously to $A$, but with the $D$ and $T$ beam ion densities included with the thermal densities. The volume average of A increases approximately linearly with the fraction of $\mathrm{T}-\mathrm{NBI}$ power, $\mathrm{PT} / \mathrm{PB}$. At 0.5 sec of NBI, which is near the time of peak neutron emission, it increases as

$$
<A>\approx 1.9+0.7 *\left(P_{T} / P_{B}\right)
$$

At this time $\left\langle A_{\text {tot }}>\right.$ is approximately $15 \%$ higher than $\langle A\rangle$.

The magnetically determined total energy confinement time, $\tau_{E}$ increases with $\langle A\rangle$ and $\left\langle A_{\text {tot }}\right\rangle$. The ratios of $\tau_{E}$ with DT-NBI to $\tau_{E}$ in comparable D-only NBI discharges are plotted versus $\left\langle A_{\text {tot }}\right\rangle$ in Fig. 4. The least squares fit gives a power of 0.72 for this enhancement. The power for the fit to $\langle A\rangle$ is 0.75 .

The plasma plus beam energy and the total energy confinement time increase $\sim 15-20 \%$ in changing the $\mathrm{NBI}$ mix from D-only to $\approx 50: 50 \mathrm{D}: \mathrm{T}$, and again another $~$ 8-10\% in changing further to $100 \%$ T-NBI. Effects contributing to these changes are 1) increased stored energy in the NBI ions, 2) altered heating of $\mathrm{T}$ beam ions, 3) stored energy of the fast alpha particles, 4) alpha heating, and 5) an isotopic mass effect. Simulations made before the DT campaign [6] incorporating 1-4 indicated the change would be about half of what is observed. 
The fraction of the total energy stored in the beams is large during the first 0.3 sec of NBI, and decreases in time as the electron density increases and more of th. beam ions thermalize. At $0.5 \mathrm{sec}$ of NBI, the beam fraction decreases to $40-50 \%$. This fraction is plotted versus $\left\langle A_{\text {tot }}>\right.$ in Fig. 5 for the sets of discharges used in Fig. 4. It does not vary significantly with $\left\langle A_{\text {tot }}\right\rangle$, so changes in the beam ion energy do not have a significant direct effect on the increase in total energy with $\left\langle A_{\text {tot }}\right\rangle$. The energy fraction in thermal ions shows a slight increase with $\left\langle A_{\text {tot }}\right\rangle$, and the fraction in electrons shows a slight decrease. The energy fraction in alphas peaks near $5 \%$ for intermediate $\left\langle A_{\text {tot }}\right\rangle$, which is where the fusion yield is largest.

The profiles of $A$ in DT-NBI, and especially in T-only NBI discharges peak near the plasma center. The profiles of the increase in total energy density, $\Delta w_{t o t} D T$ $\equiv w_{\text {tot }} \mathrm{DT}-w_{\text {tot }}{ }^{D}$ and $\Delta w_{\text {tot }}{ }^{\top} \equiv w_{\text {tot }}{ }^{\top}-w_{\text {tot }}{ }^{D}$ have shapes that are similar to the profiles of $\Delta A_{\text {tot }} D T \equiv A_{\text {tot }} D T-A_{\text {tot }}{ }^{D}$ and $\Delta A_{\text {tot }}{ } \equiv A_{\text {tot }}{ }^{\top}-A_{\text {tot }}{ }^{D}$. This suggests that the strong isotopic scaling exists throughout the plasma profile.

\section{Alpha Heating Effects}

Although the volume-integrated electron energy is relatively insensitive to $\left\langle A_{\text {tot }}\right\rangle$, as shown in Fig. 5, the central $T_{e}$ measured by ECE increases up to $2 \mathrm{keV}$ in DT plasmas. Except in plasmas with extreme lithium pellet conditioning, the central electron density is relatively constant, and $w_{e}(0)$ increases significantly. Significant increases in $T_{i}$ profiles are also observed with DT-NBI. The increase in $T_{e}$ could be caused by 1) alpha heating, 2) ion-electron coupling, and 3) an intrinsic isotopic effect. The computed peak alpha-electron heating is $0.15 \mathrm{MW} / \mathrm{m}^{3}$. The beamelectron heating with T-NBI is calculated to decrease $\mathrm{w}_{\mathrm{e}}(0)$.

These various effects can be studied by comparing modeling results for D-, DT-, and T-NBI discharges. The electron thermal conductivity, $\chi_{e}$ deduced by TRANSP from D-only and DT-NBI discharges can be cross substituted for predicting $T_{e}$. Also the NBI parameters can be cross substituted, and alpha heating can be turned on or off. The results of this modeling indicate that the isotopic and the alpha heating effects each cause about 1/2 of the observed $\Delta w_{e} D T$. The profiles of $\Delta w_{e} D T$ and $\Delta \mathrm{w}_{e} \mathrm{~T}^{\mathrm{are}}$ peaked at the plasma center, similar to the computed profiles of the alpha-electron heating, and more peaked than the broad profiles of $\Delta A_{\text {tot }} D T$ and $\Delta A_{\text {tot }}{ }^{D T}$.

\section{Summary}

The approximate agreement of the TRANSP modeling with various measured parameters indicates that the profiles of the computed beam ion and $D$ and $T$ densities are realistic. The beam fraction of the total energy at $0.5 \mathrm{sec}$ of $\mathrm{NBI}$ remains relatively constant, $\approx 40-50 \%$ as the isotopic mass varies. The total energy and the total energy confinement time increase approximately linearly with the mass by up to $30 \%$. The isotopic and alpha heating effects contribute in roughly equal amounts to the increase in central $\mathrm{Te}$.

This work was supported by the US Department of Energy Contract No. DE-AC0276-CHO-3073.

aOak Ridge National Laboratory

bUniversity of Wisconsin

cMassachusetts Institute of Technology

\section{References}

[1] R. J. Hawryluk, H. Adler, P. Alling, et al., Phys. Rev. Lett. 72 (1994) 3530.

2) J. D. Strachan, H. Adler, P. Alling, et al., Phys. Rev. Lett. 72 (1994) 3526.

3) R. V. Budny, M. G. Bell, H. Biglari, et al., Nucl. Fusion 32 (1992) 429.

4) R. V. Budny, D. Coster, et al., Jour. Nucl. Materials, 196-198 (1992) 462.

5] C. K. Skinner, H. Adler, R. V. Budny, et al., submitted to Nucl. Fusion.

[6] R. V. Budny, to be published in Nucl. Fusion. 
Fig 1 - Neutron Emission Components

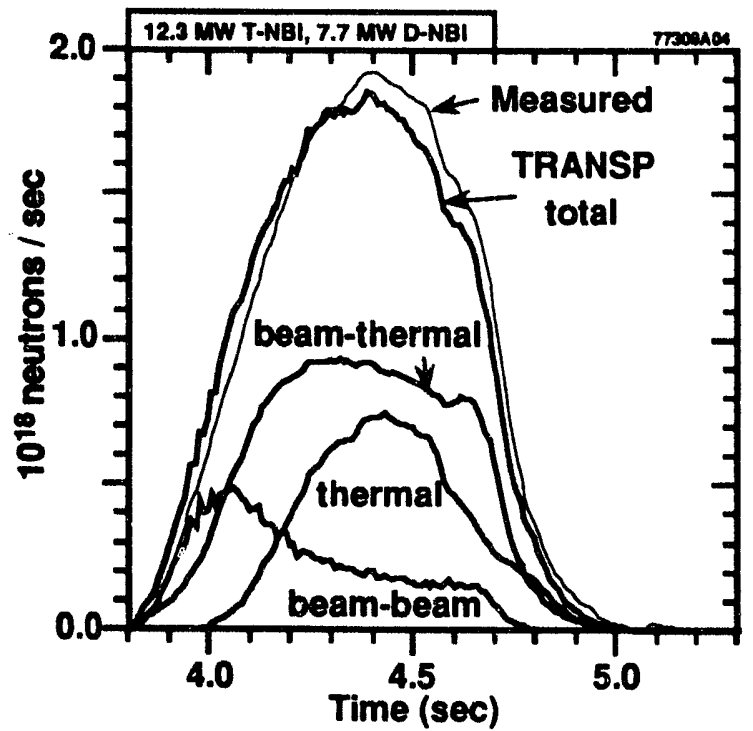

Fig 2 - Density profiles

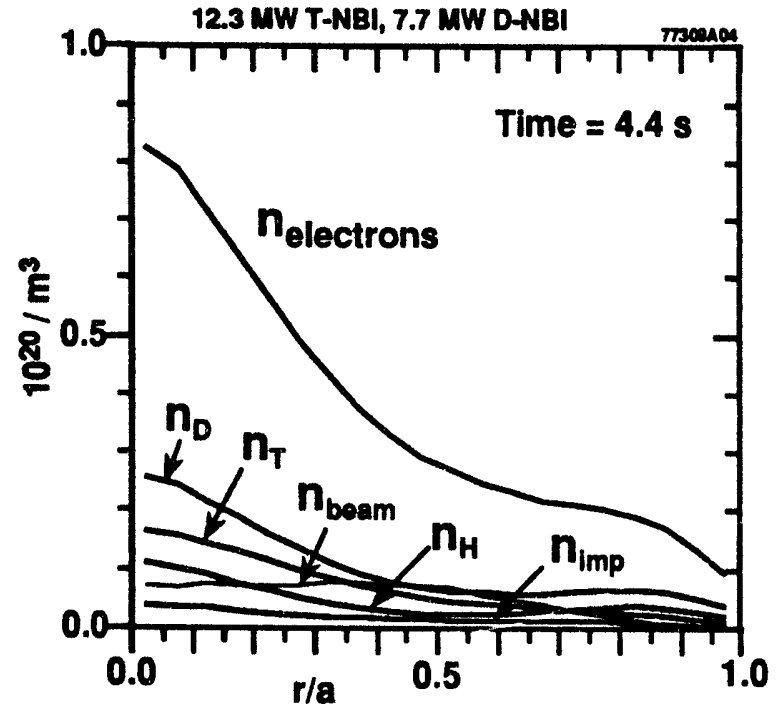

Fig 4 - Enhanced Energy Confinement

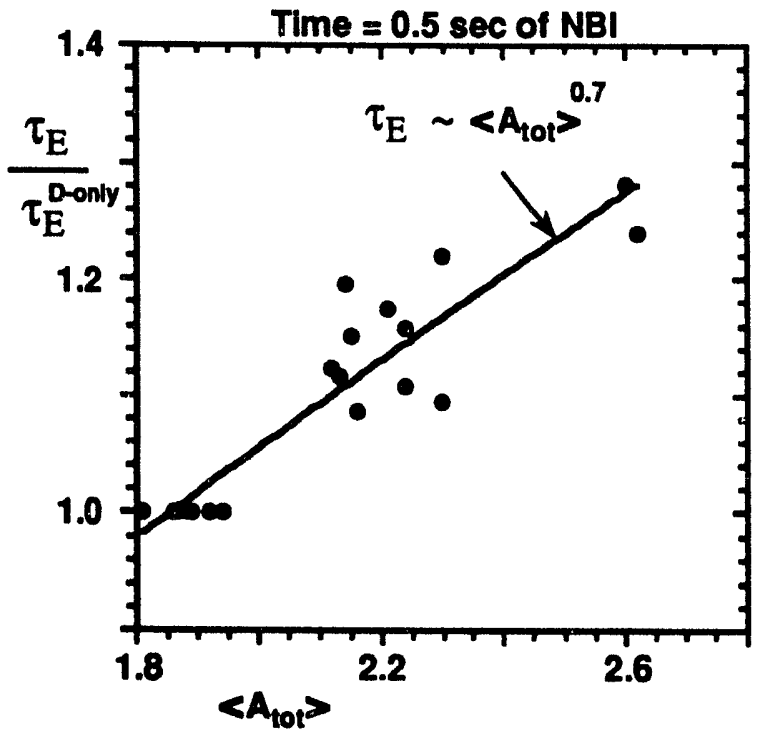

Fig 1b - Chordal DT neutron emission profiles

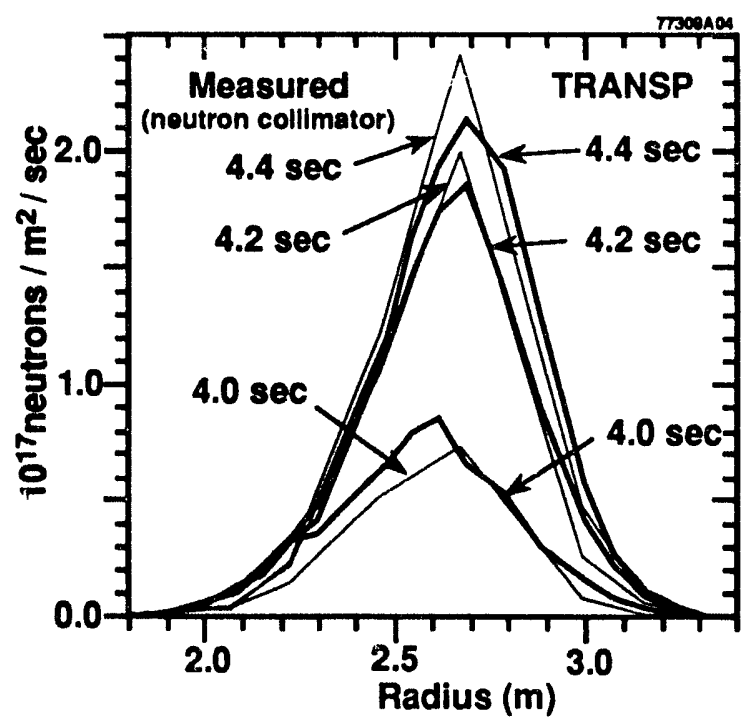

Fig 3 - Isotopic Mass Profiles

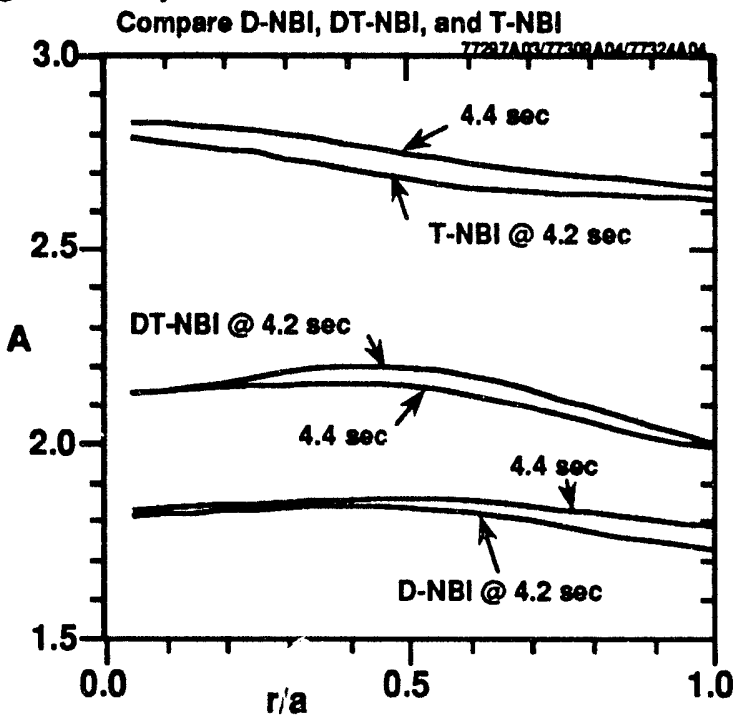

Fig 5 - Stored Energy Fractions

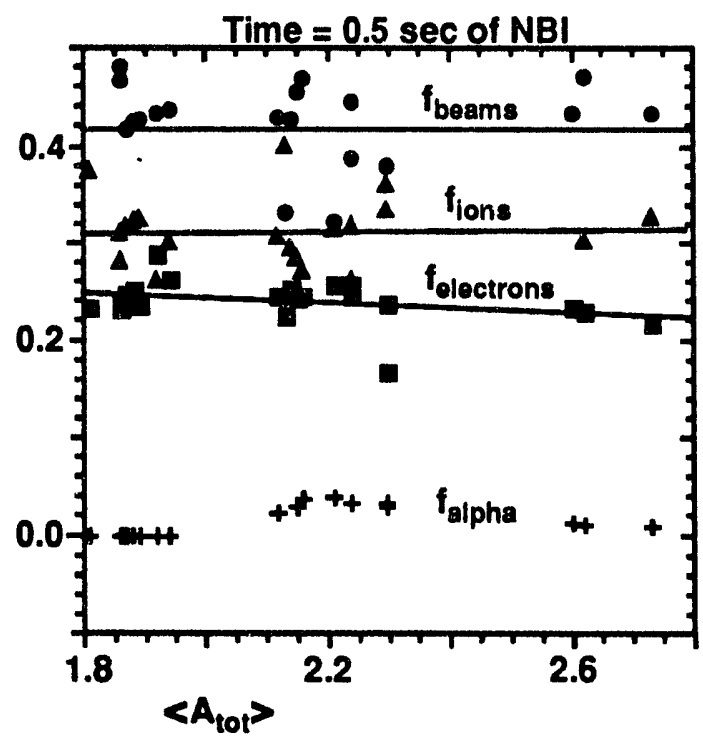




\section{EXTERNAL DISTRIBUTION IN ADDITION TO UC-420}

Dr. F. Paoloni, Univ. of Wollongong. AUSTRALIA

Prof. R.C. Cross, Univ. of Sydney, AUSTRALIA

Plasma Research Lab., Australian Nat. Univ., AUSTRALIA

Prof. I.R. Jones, Flinders Univ, AUSTRALIA

Prof. F. Cap, Inst. for Theoretical Physics, AUSTRIA

Prof. M. Heindler, Institut fur Theoretische Physik, AUSTRIA

Prof. M. Goossens, Astronomisch Instituut, BELGIUM

Ecole Royale Militaire, Lab. de Phy. Plasmas, BELGIUM

Commission-European, DG. XII-Fusion Prog., BELGIUM

Prof. R. Bouciqub, Rijksuniversiteit Gent, BELGIUM

Dr. P.H. Sakanaka, Instituto Fisica, BRAZIL

Prof. Dr. I.C. Nascimento, Instituto Fisica, Sao Paulo, BRAZIL Instituto Nacional Do Pesquisas Espaciais-INPE, BRAZIL

Documents Office, Atomic Energy of Canada Lid., CANADA

Ms. M. Morin, CCFMTokamak de Varennes, CANADA

Dr. M.P. Bachynski, MPB Technologies, Inc., CANADA

Dr. H.M. Skarsgard, Univ. of Saskatchewan, CANADA

Prof. J. Teichmann, Univ. of Montreal, CANADA

Prot. S.R. Sreenivasan, Univ. of Calgary, CANADA

Prof. R. Marchand, INRS-Energie et Materiaux, CANADA

Dr. R. Bolton, Centre canadien de fusion magnétique, CANADA

Dr. C.R. James, Univ. of Alberta, CANADA

Dr. P. Lukác, Komenského Universzita, CZECHO-SLOVAKIA

The Librarian, Culham Laboratory, ENGLAND

Library, R61, Rutherford Appleton Laboratory, ENGLAND

Mrs. S.A. Hutchinson, JET Library, ENGLAND

Dr. S.C. Sharma, Univ. of South Pacific, FIJI ISLANDS

P. Măhönen, Univ. of Helsinki, FINLAND

Prof. M.N. Bussac, Ecole Polytechnique,. FRANCE

C. Mouttet, Lab. de Physique des Milieux lonisés, FRANCE

J. Radet, CEN/CADARACHE - Bat 506, FRANCE

Prot. E. Economou, Univ. of Crete, GREECE

Ms. C. Rinni, Univ. of loannina, GREECE

Preprint Library, Hungarian Academy of Sai., HUNGARY

Dr. B. DasGupta, Saha Inst. of Nuclear Physics, INDIA

Dr. P. Kaw, Inst. for Plasma Research, INDIA

Dr. P. Rosenau, Israel Inst. of Tochnology. ISRAEL

Librarian, Intemational Center for Theo Physics, ITALY

Miss C. De Palo, Associazione EURATOM-ENEA , ITALY

Dr. G. Grosso, Istituto di Fisica del Plasma, ITALY

Prof. G. Rostangni, Istituto Gas lonizzati Del Cnr, ITALY
Dr. H. Yamato, Toshiba Res \& Devel Center, JAPAN

Prof. I. Kawakami, Hiroshima Univ., JAPAN

Prof. K. Nishikawa, Hiroshima Univ., JAPAN

Librarian, Naka Fusion Research Establishment, JAERI, JAPAN

Director, Japan Atomic Energy Research Inst., JAPAN

Frof. S. Itoh, Kyushu Univ., JAPAN

Research Info. Ctr., National Instit. for Fusion Scienco, JAPAN

Prof. S. Tanaka, Kyoto Univ., JAPAN

Library, Kyoto Univ., JAPAN

Prof. N. Inove, Univ. of Tokyo, JAPAN

Secretary, Plasma Section, Electrotechnical Lab., JAPAN

Dr. O. Mitarai, Kumamoto inst. of Technology, JAPAN

Dr. G.S. Lee, Korea Basic Sci. Ctr., KOREA

J. Hyeon-Sook, Korea Atomic Energy Research Inst., KOREA

D.I. Choi, The Korea Adv. Inst. of Sai. \& Tech., KOREA

Prof. B.S. Liley, Univ. of Waikato, NEW ZEALAND

Inst of Physics, Chinese Acad Sci PEOPLE'S REP. OF CHINA

Library, Inst. of Plasma Physics, PEOPLE'S REP. OF CHINA

Tsinghua Univ. Library, PEOPLE'S REPUBLIC OF CHINA

Z. Li, S.W. Inst Physies, PEOPLE'S REPUBLIC OF CHINA

Prot. J.A.C. Cabral, Instituto Superior Tecnico, PORTUGAL

Prof. M.A. Hellberg, Univ. of Natal, S. AFRICA

Prof. D.E. Kim, Pohang Inst. of Sci. \& Tech., SO. KOREA

Prof. C.I.E.M.A.T, Fusion Division Library, SPAIN

Dr. L. Stenflo, Univ. of UMEA, SWEDEN

Library, Royal Inst. of Technology, SWEDEN

Prof. H. Wilhelmson, Chalmers Univ. of Tech., SWEDEN

Centre Phys. Des Plasmas, Ecole Polytech, SWITZERLAND

Bibliotheek, Inst. Voor Plasma-Fysica, THE NETHERLANDS

Asst. Prof. Dr. S. Cakir, Middle East Tech. Univ., TURKEY

Dr. V.A. Glukhikh,Sci. Res. Inst. Electrophys.I Apparatus, USSR

Dr. D.D. Ryutov, Siberian Branch of Academy of Sci., USSR

Dr. G.A. Eliseev, I.V. Kurchatov Inst., USSR

Librarian, The Ukr.SSR Academy of Sciences, USSR

Dr. L.M. Kovrizhnykh, Inst. of General Physics, USSR

Kemforschungsanlage GmbH, Zentralbibliothek, W. GERMANY

Bibliothek, Inst. Fü Plasmaforschung, W. GERMANY

Prof. K. Schindler, Ruhr-Universitát Bochum, W. GERMANY

Dr. F. Wagner, (ASDEX), Max-Planck-Institut, W. GERMANY

Librarian, Max-Planck-Institut, W. GERMANY 

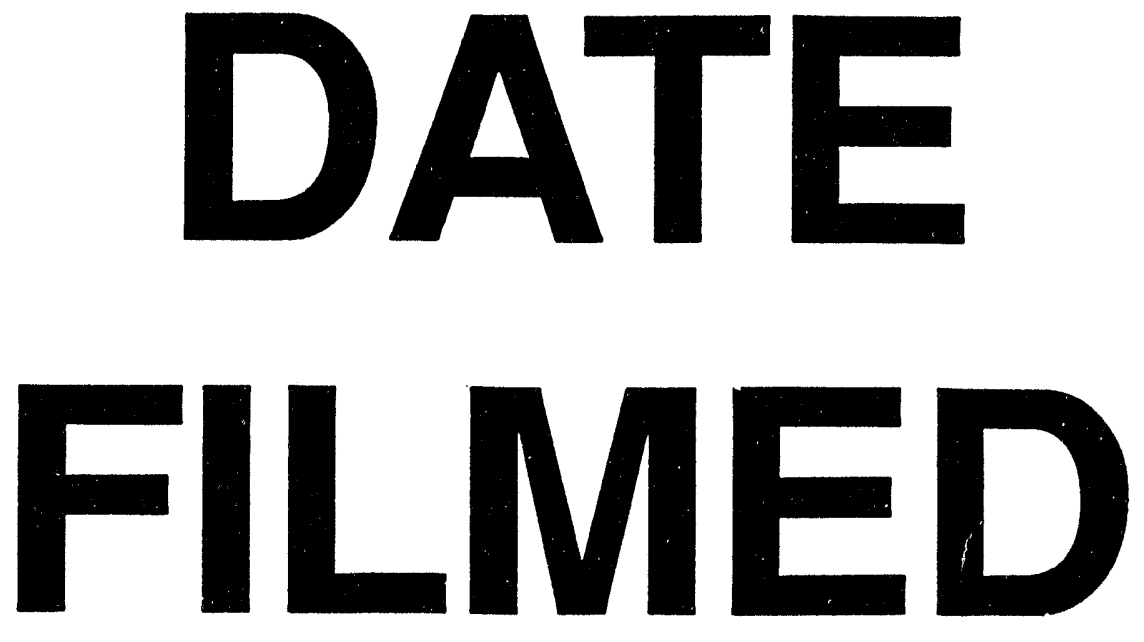

$10 / 21 / 94$
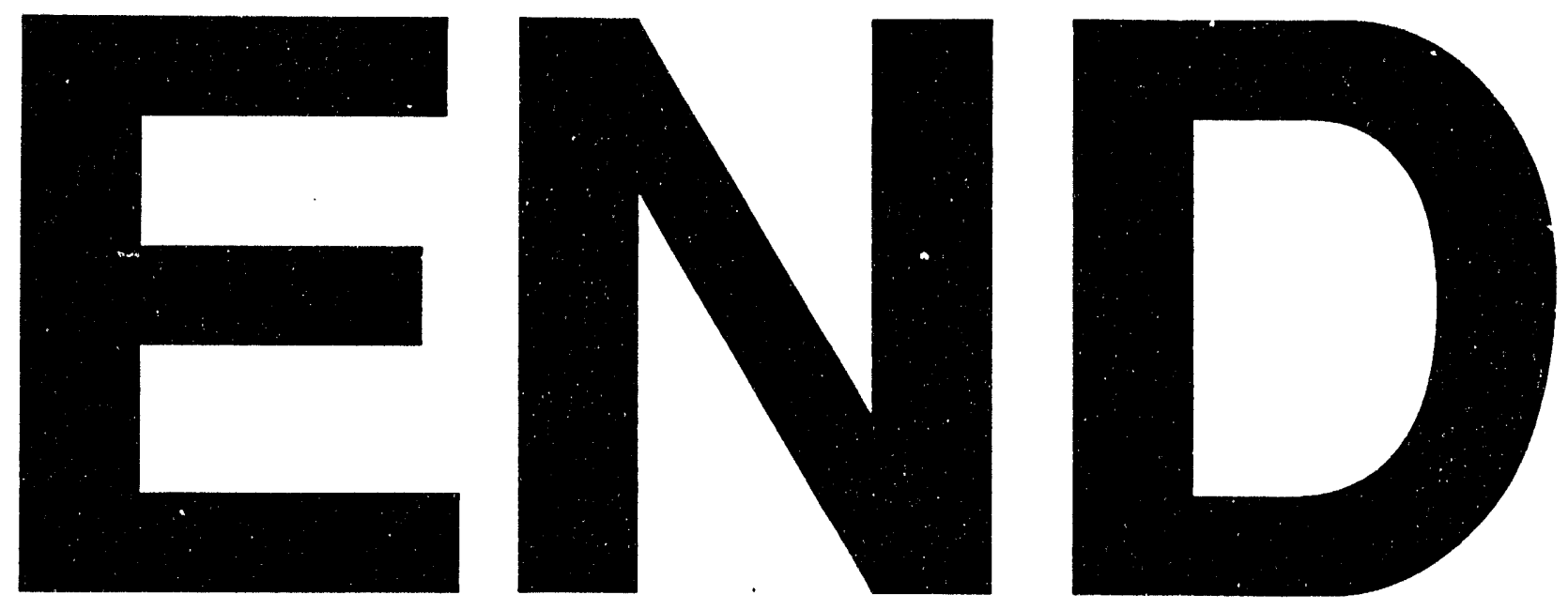
